\title{
MANGROVE ECOSYSTEM AND CLIMATE CHANGE MITIGATION: A LITERATURE REVIEW
}

\section{EKOSISTEM MANGROVE DAN MITIGASI PERUBAHAN IKLIM: SEBUAH STUDI LITERATUR}

\author{
Dian Nuraini Melati ${ }^{1}$ \\ ${ }^{1}$ Pusat Teknologi Reduksi Risiko Bencana (PTRRB), Kedeputian TPSA - Badan Pengkajian dan \\ Penerapan Teknologi (BPPT) \\ Gedung Geostech, Lantai 1, Kompleks Puspiptek Serpong, Tangerang Selatan \\ e-mail: dian.nuraini@bppt.go.id
}

\begin{abstract}
Mangrove ecosystem has high productivity both ecologically and economically. Mangrove ecosystems have the ability to store high carbon which is useful in supporting the reduction of greenhouse gas emissions. The results of previous studies have shown that mangrove ecosystems are able to store carbon three to four times greater than terestrial forests. Most of the carbon are stored in the soil. Therefore, ecosystem mangroves have an important role to mitigate climate change. However, mangroves can be effective in supporting the mitigation of carbon dioxide emissions if mangrove deforestation rates are low. However, mangroves can still contribute with great potential when conservation are maintained to increase future carbon stocks through restoration and prevent further emissions from deforestation. Existing data and prior research indicate that mangrove forests are threatened due to mangrove coverage reduction. This is caused by changes in land use. There are many conversions of mangroves into cultivation ponds, as well as conversions into agricultural land such as paddy fields and pastures, accompanied by an increase in demand for oil palm which causes land clearing. In addition, the population around the coastal area is increasing, resulting in the clearing of mangrove land for infrastructure development such as road and port construction. In order to reduce the rate of mangrove deforestation, it is necessary to conserve and restore mangroves. By preserving mangrove forests, not only maintain carbon stocks for climate change mitigation but also facilitate adaptation to climate change such as sea level rise.
\end{abstract}

Keywords: Mangrove, mitigation, carbon stock, climate change

\begin{abstract}
Abstrak
Ekosistem mangrove memiliki produktifitas yang tinggi baik itu secara ekologis maupun ekonomis. Ekosistem mangrove memiliki kemampuan menyimpan karbon yang tinggi yang bermanfaat dalam pengurangan emisi gas rumah kaca. Hasil penelitian yang pernah dilakukan sebelumnya menunjukkan bahwa ekosistem mangrove mampu menyimpan karbon tiga sampai dengan empat kali lebih besar daripada hutan 1. Mayoritas karbon tersebut tersimpan di dalam tanah. Hal ini menjadikan ekosistem mangrove memiliki peranan yang penting dalam mitigasi perubahan iklim. Akan tetapi, mangrove dapat efektif dalam mendukung mitigasi emisi karbon dioksida jika tingkat deforestasi mangrove rendah. Namun demikian, mangrove tetap dapat berkontribusi memberikan potensi yang besar jika konservasi dapat dilakukan untuk meningkatkan cadangan karbon di masa depan melalui restorasi dan mencegah emisi dari deforestasi. Data dan penelitian yang ada menunjukkan bahwa hutan mangrove terancam akibat berkurangnya tutupan mangrove. Hal ini disebabkan oleh terjadinya perubahan penggunaan lahan. Banyak dijumpai konversi mangrove menjadi kolam budidaya, dan juga konversi menjadi lahan pertanian seperti sawah dan juga padang rumput, disertai peningkatan permintaan kelapa sawit yang menyebabkan terjadinya pembukaan lahan. Ditambah pula dengan populasi di sekitar wilayah pesisir yang semakin bertambah sehingga terjadi pembukaan lahan mangrove untuk kepentingan pembangunan infrastruktur seperti
\end{abstract}


pembangunan jalan dan pelabuhan. Dalam rangka mengurangi laju deforestasi hutan mangrove, maka diperlukan konservasi dan restorasi mangrove. Dengan menjaga kelestarian hutan mangrove, tidak hanya menjaga cadangan karbon untuk mitigasi perubahan iklim tetapi juga memfasilitasi adaptasi terhadap perubahan iklim seperti kenaikan muka air laut.

Kata kunci: Mangrove, mitigasi, cadangan karbon, perubahan iklim 


\section{PENDAhULUAN}

\subsection{Latar Belakang}

Ekosistem mangrove memiliki produktifitas yang tinggi baik itu secara ekologis maupun ekonomis. Hutan mangrove menyediakan banyak jasa lingkungan seperti perlindungan daerah pesisir dari bahaya tsunami, badai, erosi maupun kenaikan muka air laut. Selain itu juga menyediakan sumber makanan dari sektor perikanan, dan juga dapat mendukung wisata bahari. Hutan mangrove ini berada di area pasang surut yang terletak di antara laut dan daratan pada daerah tropis dan subtropis dengan lintang antara $30^{\circ} \mathrm{LU}$ dan $30^{\circ} \mathrm{LS}$. Mangrove tumbuh pada lingkungan dengan salinitas tinggi, suhu tinggi, pasang surut yang ekstrim, sedimentasi tinggi, dan tanah anaerobik berlumpur (Giri et al., 2011).

Mangrove merupakan ekosistem yang kaya akan karbon dan memiliki peranan penting dalam regulasi iklim, yaitu dengan kemampuan menyimpan karbon dalam jumlah yang besar sebagai upaya mengimbangi emisi antropogenik $\mathrm{CO}_{2}$ (Mcleod et al., 2011). Karbon yang tersimpan dalam mangrove ini dikenal dengan istilah "blue carbon" atau karbon biru. Menurut Alongi et al. (2014), istilah blue carbon merujuk pada pelestarian karbon pada ekosistem akuatik, terutama pada tanah dan sedimen, dan saat ini semakin banyak digunakan pada proyek yang bertujuan meningkatkan simpanan karbon dengan memperluas tutupan mangrove.

Selain mangrove, ekosistem karbon biru lainnya yaitu rawa pantai (saltmarsh), padang lamun (seagrass), dan mangrove. Karbon biru ini menarik perhatian internasional karena peranannya dalam mitigasi perubahan iklim sebagai akibat tingginya simpanan karbon yang terkandung. Konsep karbon biru diperkenalkan di tahun 2009 pada laporan kajian hasil kolaborasi antara United Nations Environmental Programme (UNEP), Food and Agriculture Organization of the United Nations (FAO), dan Intergovernmental Oceanographic Commission of the United Nations Educational, Scientific and Cultural Organization (IOC/UNESCO) dimana peran ekosistem pesisir seperti rawa pantai, mangrove, dan padang lamun dalam menyerap karbon untuk mengurangi emisi adalah sangat penting dan perlu untuk dilindungi dan direstorasi dengan tujuan menjaga dan memperluas kemampuannya dalam menyimpan karbon (Nelleman et al., 2009).
Secara global, data dari Global Mangrove Watch (GMW, 2019) menunjukkan bahwa total luas mangrove di tahun 1996 adalah 142.865 $\mathrm{km}^{2}$, dan di tahun 2016 luas mangrove secara global adalah $136.717 \mathrm{~km}^{2}$ (Richards et al., 2020). Dengan demikian terjadi deforestasi hutan mangrove sekitar $8.050,4 \mathrm{~km}^{2}$ yang disebabkan oleh faktor alam maupun manusia. Sedangkan di Indonesia, penurunan hutan mangrove antara tahun 1985 sampai dengan 2019 mencapai $4.300 \mathrm{~km}^{2}$, atau setara dengan laju deforestasi mencapai 126,47 $\mathrm{km}^{2}$ (Arifanti, 2020).

Mengingat pentingnya mangrove sebagai ekosistem dengan kemampuan menyimpan karbon yang tinggi, laju deforestasi pada ekosistem ini tentu saja perlu mendapat perhatian. Laju deforestasi dan degradasi yang cepat dapat membawa konsekuensi yang negatif dan mempengaruhi iklim dan komposisi atmosfer (Giri et al., 2011). Dalam konteks tersebut, kajian ini melakukan studi literatur mengenai peran ekosistem mangrove terhadap mitigasi perubahan iklim terkait dengan kemampuan penyimpanan (stok) karbon pada ekosistem mangrove, peran eksosistem mangrove dalam mitigasi perubahan iklim, serta tantangan dan peluang yang dijumpai dalam mendukung mitigasi perubahan iklim.

\subsection{Tujuan Penelitian}

Tujuan dari penelitian ini adalah untuk mengetahui peran ekosistem mangrove dalam mitigasi perubahan iklim. Studi literatur dilakukan untuk melakukan kajian dan pendalaman dalam mendapatkan informasi mengenai potensi ekosistem mangrove dalam menekan dampak perubahan iklim.

\section{BAHAN DAN METODE}

\subsection{Bahan}

Dalam studi ini, bahan-bahan yang digunakan adalah artikel-artikel maupun jurnal ilmiah nasional dan internasional. Literatur tersebut digunakan sebagai referensi dalam menggali informasi mengenai peran hutan mangrove dalam upaya memitigasi perubahan iklim.

\subsection{Metode}

Studi dilakukan dengan langkah-langkah sebagai berikut:

1. Melakukan studi literatur yang meliputi pengumpulan data, informasi, dan studi 
terkait yang dilakukan melalui penelusuran artikel, laporan, maupun jurnal ilmiah baik nasional maupun internasional.

2. Melakukan studi dan membuat deskripsi mengenai stok karbon dalam ekosistem mangrove.

3. Melakukan studi dan membuat deskripsi mengenai peran ekosistem mangrove pada mitigasi perubahan iklim.

4. Melakukan studi dan membuat deskripsi mengenai tantangan dan peluang ekosistem mangrove dalam mendukung mitigasi perubahan iklim.

\section{HASIL DAN PEMBAHASAN}

\subsection{Karbon Tersimpan pada Ekosistem Mangrove}

Ekosistem mangrove memiliki peranan penting dalam menyimpan karbon (C), diantaranya pada sedimen, biomassa di atas tanah seperti daun, batang, ranting, dan di bawah tanah seperti akar, dan juga diantara bagian tumbuhan yang telah mati seperti kayu mati dan seresah (Mcleod et al., 2011). Ada sekitar 70 macam spesies mangrove yang hidup di sekitar pesisir subtropis dan tropis (Spaulding et al., 2010). Biomasa hutan mangrove mencapai nilai tertinggi di daerah ekuator.

Donato et al. (2011) melakukan perhitungan karbon tersimpan pada keseluruhan ekosistem mangrove yang terdiri atas pohon dan kayu mati, kandungan karbon dalam tanah di 25 hutan mangrove sekitar wilayah Indo-Pasifik yang terletak pada garis lintang $8^{\circ}$ LS-22ㄴ LU dan garis bujur $90^{\circ}-163^{\circ}$ BT dimana luasan mangrove dan keanekaragamannya adalah yang terbesar. Area ini meliputi Mikronesia timur (Kosrae); Mikronesia barat (Yap dan Palau); Sulawesi, Jawa, dan Bali (Indonesia); dan Sundarbans (Delta Ganges-Brahmaputra, Bangladesh). Hasil penelitian menunjukkan bahwa mangrove termasuk hutan yang kaya akan karbon di daerah tropis yang memiliki rerata karbon sebesar $1.023 \mathrm{Mg}$ karbon per hektar. Pada sistem ini, sekitar 49-98\% simpanan karbon terdapat pada tanah yang kaya organik di kedalaman 0,5 m sampai dengan $3 \mathrm{~m}$.

Sedimen pada ekosistem mangrove yang sehat tidak sama dengan tanah di daratan (Mcleod et al., 2011), dimana sedimen ini tidak mengalami saturasi karbon karena sedimen akan bertambah secara vertikal sebagai bentuk respon terhadap kenaikan permukaan laut. Oleh karena itu karbon tersimpan pada sedimen ekosistem mangrove akan terus bertambah sepanjang masa (Chmura et al., 2003). Hal ini pula yang menyebabkan kandungan karbon pada ekosistem mangrove lebih tinggi dibandingkan tipe hutan lainnya sperti terlihat pada Gambar 1. Pada gambar tersebut data karbon tersimpan diperoleh dari IPCC (2003).

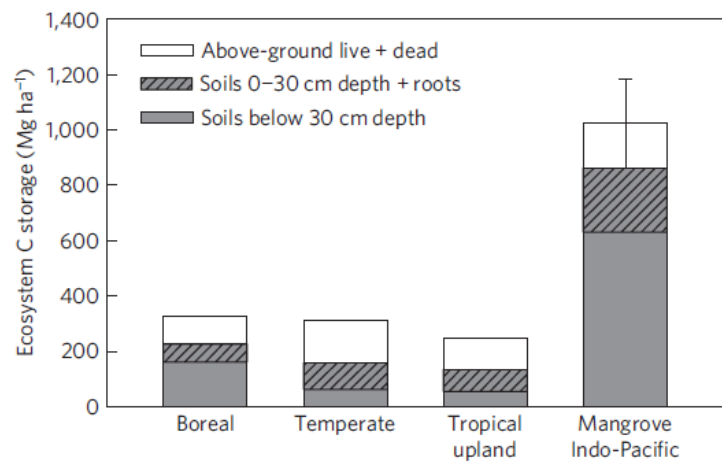

Gambar 1. Perbandingan karbon tersimpan pada mangrove (mean $\pm 95 \%$ confidence interval) dengan tipe hutan lainnya. (Sumber: Donato et al., 2011)

Untuk karbon tersimpan di Indonesia, Mudiyarso et al. (2015) melakukan perhitungan di 39 hutan mangrove yang berada pada 105으. 140ํㅡ. BT. Karbon tersimpan pada mangrove dibagi menjadi beberapa penyimpan karbon (carbon pool) yaitu biomasa di atas tanah dan pohon mati, akar di bawah tanah, kayu tumbang, dan tanah yang dibagi dalam berbagai kedalaman. Hasil penelitian menunjukkan rerata karbon di atas tanah yaitu $211 \pm 135 \mathrm{MgC}$ per ha, dengan nilai terendah ditemukan pada plot di Cilacap, Jawa $(9 \pm 10$ $\mathrm{MgC}$ per ha) dan yang tertinggi ditemukan pada plot di Bintuni, Papua Barat (367 \pm 80 MgC per ha). Sedangkan, rerata karbon tersimpan dalam tanah adalah $849 \pm 323 \mathrm{MgC}$ per ha, dengan nilai terendah $572 \pm 200 \mathrm{MgC}$ per ha di Cilacap, dan nilai tertinggi $1.059 \pm 189 \mathrm{MgC}$ per ha di Tanjung Puting. 


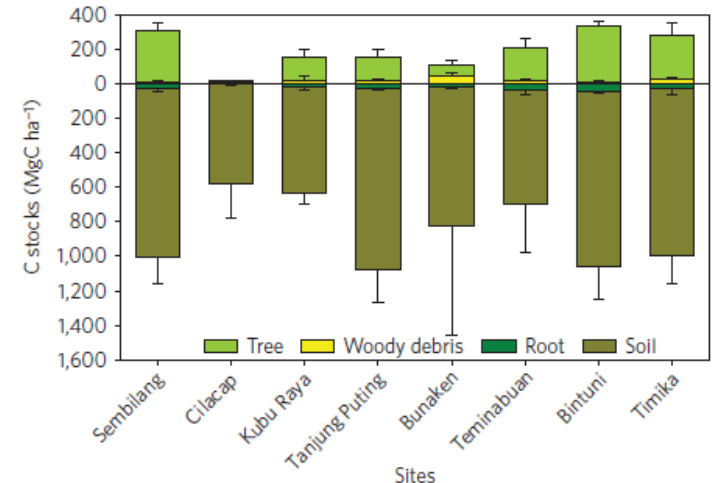

Gambar 2. Karbon tersimpan pada ekosistem mangrove yang dibagi dalam penyimpan karbon dominan. (Sumber: Murdiyarso et al., 2015)

Secara keseluruhan pada penyimpan karbon (Gambar 2), yang mencerminkan nilai total karbon tersimpan pada seluruh komponen ekosistem mangrove memiliki nilai rerata $1.083 \pm 378 \mathrm{MgC}$ per ha. Karbon tersimpan yang paling rendah ditemukan di Cilacap dengan nilai $593 \pm 210 \mathrm{MgC}$ per ha. Sedangkan nilai tertinggi ditemukan di Bintuni dengan nilai rerata karbon tersimpan adalah $1.397 \pm 191$ $\mathrm{MgC}$ per ha. Nilai estimasi karbon tersimpan pada hutan mangrove ini tentu saja menunjukkan nilai yang jauh lebih tinggi dibandingkan dengan nilai karbon tersimpan di dataran tinggi hutan tropis di Sumatra yaitu sekitar $254 \mathrm{MgC}$ per ha (Murdiyarso et al., 2002). Mudiyarso et al. (2015) menemukan bahwa mayoritas karbon pada ekosistem mangrove tersimpan sebagian besar di tanah yaitu sebesar $78 \%$.

\subsection{Peran Ekosistem Mangrove pada Mitigasi Perubahan Iklim}

Peningkatan gas rumah kaca dimana salah satunya adalah meningkatnya konsentrasi karbon dioksida $\left(\mathrm{CO}_{2}\right)$ menyebabkan terjadinya efek gas rumah kaca, atau juga dikenal sebagai pemanasan global. Pemanasan global ini lebih lanjut menyebabkan fenomena perubahan iklim. Tanaman berperan dalam menurunkan jumlah karbon di atmosfer melalui proses fotosintesis. Pada proses fotosintesis, tanaman akan membutuhkan $\mathrm{CO}_{2}$ dan $\mathrm{H}_{2} \mathrm{O}$ sehingga menyerap unsur-unsur ini dari sekitar, dan dengan bantuan sinar matahari akan mengubahnya menjadi glukosa sebagai sumber energi bagi tanaman dan juga memberikan hasil $\mathrm{H}_{2} \mathrm{O}$ dan $\mathrm{O}_{2}$ yang dapat memberikan manfaat bagi organisme lain (Purnobasuki, 2012).
Sementara itu, proses sekuestrasi karbon (carbon sequestration) pada tumbuhan dapat diartikan sebagai proses menangkap karbon dioksida dari atmosfer dan menyimpannya (Nyanga, 2020). Oleh karena itu, estimasi terhadap jumlah karbon tersimpan dalam tanaman hidup (biomassa) dapat mencerminkan $\mathrm{CO}_{2}$ yang diserap oleh tanaman dari atmosfer (Purnobasuki, 2012). Seperti penelitian-penelitian yang telah dijelaskan pada sub-bab sebelumnya, menunjukkan bahwa mangrove memiliki potensi menyimpan karbon dalam jumlah yang besar. Nyanga (2020) menyebutkan bahwa hutan mangrove mampu menyimpan karbon tiga sampai dengan empat kali lebih besar daripada hutan di daratan. Hal ini menjadikan mangrove memiliki peranan yang penting sebagai suatu ekosistem dalam upaya mitigasi perubahan iklim.

Di samping itu, proses fotosintesis yang menghasilkan karbon organik pada sebagian besar ekosistem selain ekosistem mangrove akan membusuk dan melepaskan karbon ke atmosfer dalam bentuk $\mathrm{CO}_{2}$. Akan tetapi, bahan organik yang terkandung pada ekosistem mangrove dalam jumlah yang besar tidak akan membusuk (Purnobasuki, 2012). Emisi yang dilepaskan kembali oleh hutan mangrove akan lebih kecil dibandingkan dengan hutan terrestrial. Hal ini disebabkan pembusukan yang terjadi pada serasah tanaman akuatik tidak akan melepaskan karbon.

Worthington dan Spalding (2018) menyebutkan dalam laporannya bahwa restorasi mangrove secara global memiliki potensi untuk menyimpan 69 juta ton karbon pada biomassa di atas permukaan tanah. Jumlah ini ekuivalen dengan emisi tahunan dari 25 juta rumah di Amerika. Selain itu juga restorasi mangrove mampu menyimpan 296 juta ton karbon pada tanah, dimana ekuivalen dengan emisi tahunan sejumlah 117 juta rumah di Amerika. Di Indonesia dengan total karbon tersimpan sekitar 3,14 $\mathrm{PgC}$, hutan mangrove memiliki potensi dalam upaya mitigasi perubahan iklim (Murdiyarso et al., 2015). Lebih lanjut, dengan upaya pencegahan deforestasi hutan mangrove, akan dapat mengurangi emisi sekitar 10-31\% dari estimasi emisi tahunan sektor penggunaan lahan.

Ekosistem mangrove dikenal juga dengan ekosistem karbon biru (blue carbon ecosystem). Pada laman Kabar Hutan (2018), karbon biru menunjukkan karbon yang terserap dan tersimpan di dalam laut maupun ekosistem pesisir. Karbon biru merupakan karbon yang tersimpan dalam ekosistem akuatik, terutama 
pada tanah dan sedimen. Istilah karbon biru banyak digunakan pada proyek-proyek yang bertujuan meningkatkan karbon tersimpan dengan cara meningkatkan tutupan mangrove (Alongi, 2014). Harapannya adalah bahwa dengan restorasi mangrove maka akan turut membantu mengatasi perubahan iklim.

Taillardat et al. (2018) melakukan studi estimasi sekuestrasi mangrove pada berbagai negara, dan menunjukkan bahwa mangrove dapat berpotensi dalam mitigasi emisi karbon dioksida jika tingkat deforestasi mangrove rendah. Beberapa negara seperti Malaysia dan Myanmar menunjukkan bahwa potensi karbon tersimpan dari hutan mangrove yang tersisa lebih kecil dibandingkan emisi karbon sebagai akibat dari deforestasi mangrove. Meskipun beberapa negara tersebut tidak dapat berkontribusi dalam mitigasi emisi untuk saat ini, namun akan tetap dapat berkontribusi memberikan potensi yang besar jika konservasi dapat dilakukan untuk meningkatkan sekuestrasi karbon di masa depan melalui restorasi dan mencegah emisi lebih lanjut dari deforestasi.

\subsection{Tantangan dan Peluang dalam Mitigasi Perubahan Iklim}

Pada kenyataannya, keberadaan hutan mangrove terancam akibat berkurangnya tutupan mangrove. Hal ini disebabkan oleh terjadinya perubahan penggunaan lahan. $\mathrm{Di}$ Asia Tenggara, banyak dijumpai konversi mangrove menjadi kolam budidaya, dan juga konversi menjadi lahan pertanian seperti sawah dan juga padang rumput, disertai juga peningkatan permintaan kelapa sawit yang menyebabkan terjadinya pembukaan lahan (Worthington dan Spalding, 2018). Ditambah pula dengan populasi di sekitar wilayah pesisir yang semakin bertambah sehingga terjadi pembukaan lahan mangrove untuk kepentingan pembangunan infrastruktur seperti pembangunan jalan dan pelabuhan.

\section{Gain Loss I Net}

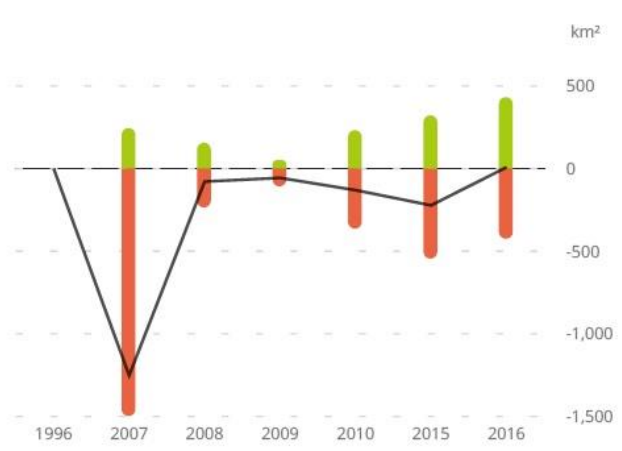

Gambar 3. Perubahan tutupan mangrove di Indonesia pada periode 1996-2016 (Sumber: Global Mangrove Watch, 2019)

Hasil studi dari Worthington et al. (2020) menunjukkan bahwa luas mangrove secara global di tahun 1996 adalah $141.945 \mathrm{~km}^{2}$ dan berkurang menjadi $135.870 \mathrm{~km}^{2}$ di tahun 2016 . Dari studi ini diketahui bahwa hilangnya mangrove terbesar secara berturut-turut terjadi di Delta Sungai Rakhine (Myanmar) sebesar $316,2 \mathrm{~km}^{2}$; Delta Mahakam (Kalimantan, Indonesia) sebesar 277,6 km²; Delta Kayan (Kalimantan, Indonesia) sebesar $239,8 \mathrm{~km}^{2}$, pesisir delta di bagian utara Brazil sebesar $170,1 \mathrm{~km}^{2}$, dan delta Sesayap (Kalimantan, Indonesia) sebesar $147,4 \mathrm{~km}^{2}$. Menurut data dari Global Mangrove Watch (2019), luas mangrove di Indonesia berkurang sebesar $1.731,54 \mathrm{~km}^{2}$ pada tahun 1996 sampai dengan 2016. Gambar 3 menunjukkan perubahan tutupan mangrove di Indonesia dari tahun 1996 sampai dengan 2016. Nilai gain menunjukkan adanya peningkatan tutupan mangrove, nilai loss menunjukkan jumlah hilangnya tutupan mangrove. Sedangkan net menunjukkan perubahan yang terjadi pada periode tersebut yang merupakan selisih antara gain dan loss. Dari Gambar 3 tersebut dapat dilihat nilai net yang menunjukkan minus dari tahun ke tahun. Trend ini menggambarkan bahwa setiap tahun lebih banyak terjadi deforestasi dibandingkan dengan penambahan tutupan mangrove.

Dalam rangka mengurangi laju deforestasi hutan mangrove, maka diperlukan konservasi dan restorasi mangrove. Dengan menjaga kelestarian hutan mangrove, tidak hanya menjaga cadangan karbon untuk mitigasi perubahan iklim tetapi juga memfasilitasi dalam rangka adaptasi terhadap perubahan iklim seperti kenaikan muka air laut (Donato et al., 
2011). Dari studi yang dilakukan oleh Kulp dan Strauss (2019), lebih dari $70 \%$ dari populasi global yang tinggal di China, Bangladesh, India, Vietnam, Indonesia, Thailand, Filipina, dan Jepang terancam oleh kenaikan muka air laut.

Hasil studi dari Worthington dan Spalding (2018) menunjukkan bahwa ada sekitar 2.500 area yang dilindungi dengan hutan mangrove di dalamnya seluas $54.000 \mathrm{~km}^{2}$, atau sekitar $39 \%$ hutan mangrove yang tersisa di dunia. Studi ini memperlihatkan bahwa tingkat degradasi di area yang terlindungi adalah kurang dari setengahnya dibandingkan dengan hutan mangrove yang berada di luar area yang terlindungi. Disebutkan pula beberapa negara dengan tingkat tutupan mangrove dan luasan mangrove yang yang tinggi di dalam area terlidungi seperti Bangladesh, Brazil, dan Amerika. Sedangkan Indonesia dengan luasan mangrove terbesar di dunia hanya memiliki $24 \%$ dari hutan mangrove di dalam area terlindungi.

Dalam mendukung upaya mitigasi perubahan iklim di tingkat global, Perjanjian Paris dalam Konvensi PBB untuk Perubahan Iklim atau yang dikenal dengan United Nations Framework Convention on Climate Change (UNFCCC) Paris Agreement mewajibkan seluruh pihak untuk mendukung aksi mitigasi dan membuat target-target dalam bentuk Nationally Determined Contribution (NDC) terkait rencana aksi mitigasi perubahan iklim bagi setiap negara. Dalam hal ini, proteksi dan restorasi mangrove menjadi bagian dari rencana aksi tersebut. Selain itu, skema perdagangan karbon melalui penurunan emisi melalui deforestasi dan degradasi hutan (Reducing Emissions from Deforestation and Forest Degradation Plus/REDD+) dan proyek mitigasi iklim lainnya yang menjaga cadangan karbon dan juga aktivitas terkait restorasi mangrove menjadi sangat penting. Hal ini tidak hanya untuk menjaga dan merestorasi cadangan karbon dan juga jasa lingkungan, tetapi juga untuk menjaga karbon tersimpan agar tidak terlepaskan ke atmosfer (Alongi et al., 2015).

\section{KESIMPULAN}

Dari hasil studi literatur dapat diambil kesimpulan terkait peran ekosistem mangrove terhadap mitigasi perubahan iklim sebagai berikut:

1. Mangrove memiliki potensi cadangan karbon yang besar, dengan nilai yang cadangan karbon tiga sampai dengan empat kali lebih besar dari cadangan karbon pada hutan terrestrial.

2. Kemampuan mangrove dalam menyimpan cadangan yang besar membawa manfaat dalam upaya menurunkan emisi gas rumah kaca.

3. Mangrove dapat efektif dalam mendukung mitigasi emisi gas rumah kaca bila tingkat deforestasi mangrove rendah.

4. Terjadinya deforestasi banyak disebabkan oleh konversi mangrove menjadi kolam budidaya, dan juga konversi menjadi lahan pertanian, disertai juga pembukaan lahan akibat peningkatan permintaan kelapa sawit dan pembangunan infrastruktur.

5. Konservasi dan restorasi mangrove dalam rangka mengurangi laju deforestasi tidak hanya dapat menjaga cadangan karbon untuk mitigasi perubahan iklim tetapi juga dapat memfasilitasi adaptasi terhadap perubahan iklim seperti kenaikan muka air laut.

\section{PERSANTUNAN}

Penulis mengucapkan terima kasih kepada dewan redaksi serta reviewer atas masukan yang diberikan sehingga artikel ini dapat diterbitkan. Dengan ini, penulis menyampaikan bahwa artikel ini tidak menimbulkan potensi konflik kepentingan.

\section{DAFTAR PUSTAKA}

Alongi, D. M. 2014. Carbon cycling and storage in mangrove forests. Annual review of marine science, 6, 195-219.

Alongi, D. M., D. Murdiyarso, J. W. Fourqurean, J. B. Kauffman, A. Hutahaean, S. Crooks, C. E. Lovelock, J. Howard, D. Herr, M. Fortes, E. Pidgeon, dan T. Wagey. 2015. Indonesia's blue carbon: a globally significant and vulnerable sink for seagrass and mangrove carbon. Wetlands Ecology and Management, 24(1), 3-13.

Arifanti, V. B. 2020. Mangrove management and climate change: a review in Indonesia. In IOP Conference Series: Earth and Environmental Science (Vol. 487, No. 1, p. 012022). IOP Publishing.

Chmura, G.L., S.C. Anisfeld, D.R. Cahoon, dan J.C. Lynch. 2003. Global carbon sequestration in tidal, saline wetland soils. Global Biogeochem Cy 17: 1111; doi:10.1029/2002GB001917.

Kabar Hutan. 2018. Apa itu Karbon biru?. [terhubung

berkala] 
https://forestsnews.cifor.org/55426/apa-itukarbon-biru?fnl=en [21 Agustus 2021].

Donato, D. C., J. B. Kauffman, D. Murdiyarso, S. Kurnianto, M. Stidham, dan M. Kanninen. 2011. Mangroves among the most carbonrich forests in the tropics. Nature geoscience, 4(5), 293-297.

Giri, C., E. Ochieng, L. L. Tieszen, Z. Zhu, A. Singh, T. Loveland, J. Masek, dan N. Duke. 2011. Status and distribution of mangrove forests of the world using earth observation satellite data. Global Ecology and Biogeography, 20(1), 154-159.

Global Mangrove Watch (GMW). 2019. Global Mangrove Watch1996-2016.UNEP-WCMC Data Viewer.

IPCC. 2003. Intergovernmental Panel on Climate Change (IPCC) in Good Practice Guidance for Land use, Land-use Change, and Forestry (eds Penman, J. et al.). Institute for Global Environmental Strategies.

Kulp, S. A., dan B. H. Strauss. 2019. New elevation data triple estimates of global vulnerability to sea-level rise and coastal flooding. Nature communications, 10(1), 112.

Mcleod, E., G.L. Chmura, S. Bouillon, R. Salm, M. Björk, C. M. Duarte, C.E. Lovelock, W.H. Schlesinger, dan B.R. Silliman. (2011). A blueprint for blue carbon: toward an improved understanding of the role of vegetated coastal habitats in sequestering CO2. Frontiers in Ecology and the Environment, 9(10), 552-560.

Murdiyarso, D., J. Purbopuspito, J. B. Kauffman, M. W. Warren, S. D. Sasmito, D. C. Donato, S. Manuri, H. Krisnawati, S. Taberima, dan S. Kurnianto. 2015. The potential of Indonesian mangrove forests for global climate change mitigation. Nature Climate Change, 5(12), 1089-1092.

Murdiyarso, D., M. Van Noordwijk, U. R. Wasrin, T. P. Tomich, dan A. N. Gillison. 2002. Environmental benefits and sustainable land-use options in the Jambi transect, Sumatra. J. Veg. Sci. 13, 429_438.

Nelleman, C., E. Corcoran, C. M. Duarte, L. Valdés, C. DeYoung, L. Foseca, G. Grimsditch. (Eds.). 2009. Blue Carbon: A Rapid Response Assessment. United Nations Environmental Programme and GRID-Arendal: Arendal, Norway.

Nyanga, C. 2020. The Role of Mangroves Forests in Decarbonizing the Atmosphere. In Carbon-Based Material for Environmental Protection and Remediation. IntechOpen.
Purnobasuki, H. 2012. Pemanfaatan hutan mangrove sebagai penyimpan karbon. Buletin PSL Universitas Surabaya, 28(3-5), 1-6.

Richards, D. R., B. S. Thompson, dan L. Wijedasa. 2020. Quantifying net loss of global mangrove carbon stocks from 20 years of land cover change. Nature communications, 11(1), 1-7.

Spaulding M, M. Kainuma, dan L. Collins. 2010. World Atlas of Mangroves. London: Earthscan.

Taillardat, P., D. A. Friess, dan M. Lupascu. 2018. Mangrove blue carbon strategies for climate change mitigation are most effective at the national scale. Biology Letters, 14(10), 20180251.

Worthington, T., dan M. Spalding. 2018. Mangrove Restoration Potential: A global map highlighting a critical opportunity.https://doi.org/10.17863/CAM.3 9153.

Worthington, T. A., P. S. E. zu Ermgassen, D. A. Friess, K. W. Krauss, C. E. Lovelock, J. Thorley, R. Tingey, C. D. Woodroffe, P. Bunting, N. Cormier, D. Lagomasino, R. Lucas, N. J. Murray, W. J. Sutherland, dan M. Spalding. 2020. A global biophysical typology of mangroves and its relevance for ecosystem structure and deforestation. Scientific reports, 10(1), 1-1 
